\title{
Peonidin-3-glucoside extends the lifespan of Caenorhabditis elegans and enhances its tolerance to heat, UV, and oxidative stresses
}

\author{
John Sylvester B. Nas ${ }^{\mathrm{a}, \mathrm{b}, \mathrm{c}}$, Rafael Vincent M. Manalo ${ }^{\mathrm{a}}$, Paul Mark B. Medina ${ }^{\mathrm{a}, *}$ \\ a Biological Models Laboratory, Department of Biochemistry and Molecular Biology, College of Medicine, \\ University of the Philippines Manila, Manila 1000 Philippines \\ b Department of Biology, College of Arts and Sciences, University of the Philippines Manila, \\ Manila 1000 Philippines \\ c Department of Medical Technology, Institute of Arts and Sciences, Far Eastern University, \\ Manila 1000 Philippines
}

*Corresponding author, e-mail: pmbmedina@post.upm.edu.ph

Received 24 Aug 2020

Accepted 3 May 2021

\begin{abstract}
Anthocyanins have long been established for their benefits to various organisms, ranging from lifespan extension and healthspan improvement in animal models to enhanced immunity and organ function in humans. In Asia, staple food, such as potatoes and rice, contains peonidin, a flavylium-bearing anthocyanin. However, its benefits have only been demonstrated in crude or partially purified extracts, with scarce data on its purified form. In this study, peonidin-3-glucoside (P3G) was tested for antioxidant properties and was administered to Caenorhabditis elegans under various forms of stresses (ultraviolet, heat, and oxidative stress). P3G showed free radical scavenging activity with an $\mathrm{EC}_{50}$ 6.9-fold higher than that of ascorbic acid but was twofold lower than that of CoQ10 (150 $\left.\mu \mathrm{g} / \mathrm{ml}\right)$. Using its sublethal concentration $(50 \mu \mathrm{g} / \mathrm{ml})$, P3G extended the lifespan of $C$. elegans by $14 \%$ greater than that of vehicle $\left(\mathrm{dH}_{2} \mathrm{O}\right)$ but comparable with CoQ10 (16\%). In addition, $50 \mu \mathrm{g} / \mathrm{ml} \mathrm{P3G} \mathrm{increased} \mathrm{the} \mathrm{pharyngeal} \mathrm{pumping} \mathrm{rate} \mathrm{of} C$. elegans by $8.3 \%$, which is an indicator of healthspan improvement. When compared with $\mathrm{dH}_{2} \mathrm{O}$ under ultraviolet (UVA), heat $\left(30{ }^{\circ} \mathrm{C}\right.$ ), and $\mathrm{H}_{2} \mathrm{O}_{2}(100 \mu \mathrm{m})$ stressors, P3G continued to increase the lifespan of C. elegans by $23 \%, 25 \%$, and $47 \%$, respectively; which CoQ10 was not able to achieve except under $\mathrm{H}_{2} \mathrm{O}_{2}$ stress. Meanwhile, egg-laying ability-which is another indicator of healthspan-did not improve with either P3G or CoQ10. Taken together, P3G enhanced the lifespan and healthspan of $C$. elegans in the presence of UV, heat, and oxidative stresses, with mechanisms possibly diverging from its antioxidant activity that warrant further investigation.
\end{abstract}

KEYWORDS: aging, anthocyanins, coenzyme Q10, longevity, pharmacodynamics

\section{INTRODUCTION}

Anthocyanins are responsible for the deep pigmentation of various parts of plants and vegetation, such as flowers, leaves, fruits, and cereal grains-at times giving them a blue, purple, or red appearance. The six known classes of anthocyanins, namely cyanidin, peonidin, delphinidin, pelargonidin, petunidin, and malvidin, are well represented in the human diet, and have been shown to have antioxidant and medicinal properties in many herbal preparations [1-3]. In addition, studies have also shown the benefits of anthocyanin-containing crude extracts in promoting longevity and stress resistance [4-6]. However, these studies do not demonstrate the separated efficacy of purified anthocyanins and maintain an unclear distinction between medicinal effects attributable to anthocyanins alone and to other phytochemicals present, as well as to their apparent modes of interaction.

In this study, peonidin-3-glucoside (P3G) was chosen as the anthocyanin of interest. It is a phytochemical commonly found in various berries [5] and is dominantly found in purple cabbage (Brassica oleracea var. capitate), purple yam (Dioscorea alata), camote tops (Ipomoea batatas), and black and red rice (Oryza sativa) here in the Philippines [7-9]. Hence, P3G is a relevant and accessible anthocyanin in the country, which warrants investigation on its medicinal properties. The protective effect of anthocyanins extracted from black rice against oxidative stress and oxidative damage in the brain leading to learning and memory impairment in mice has been reported [10]. Here, we show that P3G increases 
the lifespan and healthspan of Caenorhabditis elegans at its sublethal concentration $(50 \mu \mathrm{g} / \mathrm{ml})$ under UV (B), heat $\left(30^{\circ} \mathrm{C}\right)$, or $\mathrm{H}_{2} \mathrm{O}_{2}$ stresses, which is generally comparable to that of CoQ10 despite its lower free radical scavenging $\mathrm{EC}_{50}$. These suggest that P3G is a potentially beneficial compound for healthy aging and longevity, and this warrants further investigation on its mechanism of action, which possibly diverges from its free radical scavenging activity.

\section{MATERIALS AND METHODS}

\section{Preparation of the compounds}

Peonidin-3-glucoside (P3G) (> 97\%) and coenzyme Q10 (98\%) were procured from AS Polyphenols (Norway) and ApexBio (Texas), respectively, and were stored in powder form at $-20^{\circ} \mathrm{C}$ until further use. On the day of experimentation, P3G was dissolved in $\mathrm{dH}_{2} \mathrm{O}$ to prepare two concentrations (50 and $100 \mu \mathrm{g} / \mathrm{ml}$ ), with the stock stored at $4^{\circ} \mathrm{C}$ protected by foil and away from sources of light. Meanwhile, $150 \mu \mathrm{g} / \mathrm{ml}$ of CoQ10 was prepared according to a study that showed optimal lifespan extension at this concentration [11], with similar storage conditions.

\section{Preparation of nematode plates}

For this study, C. elegans was prepared and maintained according to Manalo and Medina [12]. Briefly, the following compounds were dissolved in $125 \mathrm{ml}$ of $\mathrm{dH}_{2} \mathrm{O}: 0.375 \mathrm{~g} \mathrm{NaCl}, 2.125 \mathrm{~g}$ bacteriological agar, and $0.3125 \mathrm{~g}$ bactopeptone. After thorough mixing, the suspension was autoclaved at 15 psi to achieve $121^{\circ} \mathrm{C}$ for $15 \mathrm{~min}$. After cooling to about $60^{\circ} \mathrm{C}, 125 \mu \mathrm{l}$ each of $1 \mathrm{M} \mathrm{CaCl}_{2}, 1 \mathrm{M} \mathrm{MgSO}_{4}$, and $5 \mathrm{mg} / \mathrm{ml}$ cholesterol in absolute ethanol were added, followed by $3.125 \mathrm{ml}$ of $1 \mathrm{M} \mathrm{K}_{3} \mathrm{PO}_{4}$. The solution was mixed at each addition and was poured via aseptic techniques to small petri plates to make nematode growth media (NGM). After sufficient cooling, $100 \mu \mathrm{l}$ of Escherichia coli strain OP50 was added onto each plate, before $30 \mathrm{C}$. elegans strain N2 nematodes were transferred via worm-picking. Worms were age-synchronized at stage L4 by placing adult worms in new NGM plates allowing them to lay eggs for $1 \mathrm{~h}$, and then removing them from the plates. The eggs laid, which were estimated to have $\pm 1 \mathrm{~h}$ age difference, were then allowed to hatch with the worms maturing to stage L4 before distributing to new NGM plates until $n=30$.

\section{Sublethal assay}

For each set-up, NGM plates containing $100 \mu \mathrm{g} / \mathrm{ml}$ of P3G was prepared for the nematodes. The concentration was based on a previous study showing optimal lifespan extension and thermotolerance by anthocyanin-containing crude blueberry extracts at $200 \mu \mathrm{g} / \mathrm{ml}[4,13]$. Since a pure anthocyanin compound was used, we intuitively used a twofold less concentration as the initial test treatment. After exposure to control or treatment, the number of live nematodes was counted after $72 \mathrm{~h}$. Each nematode was scored as alive if they were motile, or if they responded to a light stroke with a nichrome wire. Survival rate was expressed as percent survival per day of observation. The sublethal concentration was arbitrarily set to be the concentration at which survival is $\geqslant 90 \%$ ( $n=27$ or above) at $72 \mathrm{~h}$. This was chosen to maximize the sample size and statistical power of treatment groups, and to minimize any toxic effects that may confound the results. If a given concentration demonstrates lethality based on the parameters established, the concentration will be diluted twofold and retested until survival is $\geqslant 90 \%$ ( $n=27$ or above) at $72 \mathrm{~h}$.

\section{Radical scavenging activity}

For the free radical scavenging activity, P3G or CoQ10 was determined and compared with ascorbic acid. The individual compounds were diluted twofold lower for 8 times starting from $100 \mu \mathrm{g} / \mathrm{ml}$ up to $0.781 \mu \mathrm{g} / \mathrm{ml}$. After which, $10 \mu \mathrm{l}$ of each compound was mixed with $140 \mu \mathrm{l}$ of $68.5 \mu \mathrm{M} 2,2$ diphenyl-1-picryl-hydrazyl (DPPH) in each well of a 96-well plate. After $30 \mathrm{~min}$ of incubation at room temperature, absorbance was read at $517 \mathrm{~nm}$ using a UV/Vis spectrophotometer. The scavenging activity of DPPH in percentage of each sample was then calculated in triplicate. The effective concentration at $50 \%$ radical scavenging activity $\left(\mathrm{EC}_{50}\right)$ of the individual compounds was determined using GraphPad Prism version 7, (GraphPad Software, Inc.) for comparison.

\section{Longevity assay}

This assay was adopted from the study of Park et al with slight modifications [14]. Briefly, 30 stage L4 nematodes were placed on freshly prepared NGM plates under the following treatments: $\mathrm{dH}_{2} \mathrm{O}$; CoQ10 $(150 \mu \mathrm{g} / \mathrm{ml})$; and P3G (50, 25, and $12.5 \mu \mathrm{g} / \mathrm{ml}$ ). Fifty $\mu \mathrm{l}$ of different concentrations of the compounds with $E$. coli (OP50) were dispensed on top of freshly made NGM plates. Worms were 
immediately transferred directly on the dispensed compounds mixed with $E$. coli on the fresh NGM plates. This was done daily to ensure that worms were exposed to freshly prepared compounds with constant concentrations per day. The worms were exposed to the compounds ad libitum. Worms were counted every day under a bright field stereomicroscope until all the worms were dead. Nematodes were scored as alive if they were motile, or if they responded to a light poking with a nichrome wire.

In this study, mean lifespan with treatment was defined as the average lifespan of the $C$. elegans treated with different compounds, whereas mean lifespan control was defined as the average lifespan of the worm under no treatment. The difference between the mean lifespan with treatment and the mean lifespan control was obtained as percentage (\%) to determine the $\%$ change in lifespan.

\section{Measurement of egg-laying ability}

The egg laying ability was also measured according to the study of Park et al with slight modifications [14]. Briefly, 30 nematodes stage L4 were transferred to freshly prepared NGM plates with treatments or vehicle and were then allowed to lay eggs every $24 \mathrm{~h}$ before transferring to new treated plates. Egg count was then obtained by averaging the number of eggs laid by all nematodes per day. C. elegans was transferred daily to new NGM plate until no eggs were observed.

\section{Measurement of the pharyngeal pumping rate}

Similarly, the pharyngeal pumping rate was measured by counting the number of pumps per min (ppm). The pharyngeal pumping rate was measured every day using a stereomicroscope and was recorded using Amscope MD500 camera (7.5 fps, $35 \mathrm{~mm}, 1080 \mathrm{p} \mathrm{HD})$. A given cycle contraction and relaxation of the corpus and terminal bulb was counted as one pharyngeal pump [15].

\section{Stress assay}

In this study, the effect of different insults on the lifespan and healthspan of C. elegans was monitored according to the study of Park et alwith slight modifications [14]. In brief, 30 nematodes per treatment group were exposed to the sublethal concentration of P3G, $150 \mu \mathrm{g} / \mathrm{ml} \mathrm{CoQ10}$, or $\mathrm{dH}_{2} \mathrm{O}$. Subsequently, worms were exposed separately to heat, UV, or oxidative stress. No worm is exposed to more than one stressor for the entirety of the assay, and each stressor effect is evaluated separately using different groups of C. elegans nematodes.

\section{Heat stress}

For heat stress, plates containing 30 agesynchronized L4 nematodes were exposed to $30^{\circ} \mathrm{C}$ heat for $30 \mathrm{~min}$ daily using a pre-heated incubator, with the number of live nematodes recorded prior to heating. These were periodically transferred to new treated NGM plates every 3 to 4 days to prevent confounders arising from new C. elegans offspring.

\section{UV stress}

To induce photoaging, NGM plates containing 30 stage L4 nematodes were exposed to ultraviolet (UVA) radiation $\left(1300 \mu \mathrm{W} / \mathrm{cm}^{2}\right)$ at $365 \mathrm{~nm}$ for 2 min every day using a UV-GL-58 handheld lamp 3 inches above the base of the plates. Similarly, the number of live nematodes was recorded prior to UV exposure, with worms periodically transferred to new treated NGM plates to prevent confounders brought about by new $C$. elegans offspring.

\section{Oxidative stress}

In this study, oxidative stress was induced based on the protocol of Bhatla and Horvitz (2015), with slight modifications [16]. Briefly, nematodes were exposed to $100 \mu \mathrm{M}$ of freshly prepared hydrogen peroxide $\left(\mathrm{H}_{2} \mathrm{O}_{2}\right)$ solution by dropping approximately $0.2 \mu \mathrm{l}$ of the solution to the head portion of the nematodes. They were then immediately washed with $\mathrm{dH}_{2} \mathrm{O}$ by transferring them to blank water-filled plates and subsequently transferring again to a newly treated NGM plate. This was done to prevent confounders brought about by direct oxidative damage to the exterior surfaces of the nematode. The number of live nematodes was recorded after $24 \mathrm{~h}$ and prior to the next free radical exposure, with worms transferred every 3 to 4 days to prevent confounding by new $C$. elegans offspring.

\section{Statistical analyses}

In all experiments, results were analyzed as biological replicates with two trials performed. Data were presented as mean \pm SEM. Statistical analysis was done using one-way ANOVA with post-hoc Tukey's multiple comparisons test. Meanwhile, a log-rank test post-hoc Bonferroni-Holm multiple comparisons test was performed for lifespan using OASIS 2. Statistical significance was set at $p<0.05$. “*”" denotes significance compared with vehicle $\left(\mathrm{dH}_{2} \mathrm{O}\right)$, while “**" denotes significance versus $\mathrm{dH}_{2} \mathrm{O}$ and CoQ10. 
All experiments were done under Biosafety Level 1 precautions at the Biological Models Laboratory of the College of Medicine, University of the Philippines (UP) Manila. Since the in vivo model C. elegans is an invertebrate, this study was exempted for review by the Research Ethics Board of the UP Manila (2018-019-01).

\section{RESULTS AND DISCUSSION}

\section{Sublethal assay}

Two concentrations of P3G were tested for the sublethal assay. When nematodes were exposed to $100 \mu \mathrm{g} / \mathrm{ml} \mathrm{P3G}$, the survival rate at $72 \mathrm{~h}$ was $86.53 \%$. To this end, the concentration was diluted twofold and was retested in C. elegans; and with the $50 \mu \mathrm{g} / \mathrm{ml}$ P3G concentration, the worms maintained a $100 \%$ survival rate (Fig. 1A). The latter was determined to be the sublethal concentration of P3G based on the survival parameter of $\geqslant 90 \%$ ( $n=$ 27 or above) at $72 \mathrm{~h}$. Interestingly, the sublethal concentration of pure P3G is lower compared with the concentrations of crude anthocyanin extracts used in previous reports $[4,13]$. This is expected, since pure P3G intuitively produces an amplified effect compared with crude anthocyanin extracts under the assumption that synergism is unlikely to occur, and hence toxicity is also likely to be observed at lower concentrations. This suggests that for P3G at least, efficacy - and hence toxicity - is a function of anthocyanin purity. With CoQ10 treatment, three concentrations were used: 300 , 225 , and $150 \mu \mathrm{g} / \mathrm{ml}$. Both 300 and $225 \mu \mathrm{g} / \mathrm{ml}$ concentrations were lethal to $C$. elegans with survival rates of $84.31 \%$ and $88 \%$, respectively (Fig. 1B). Meanwhile, $150 \mu \mathrm{g} / \mathrm{ml} \mathrm{CoQ10}$ did not decrease the survival rate of $C$. elegans. Indeed, this sublethal dose is in line with the concentration from previous reports on its lifespan extending properties $[11,17,18]$.

\section{P3G is a stronger antioxidant than CoQ10}

For free radical scavenging, the DPPH scavenging activities of P3G and CoQ10 were significantly lower than that of ascorbic acid $\left(\mathrm{EC}_{50}=6.406 \mu \mathrm{g} / \mathrm{ml}\right)$, as shown in Fig. 2. The apparent $\mathrm{EC}_{50}$ of P3G $\left(\mathrm{EC}_{50}\right.$ $=44.27 \mu \mathrm{g} / \mathrm{ml}$ ) was twofold lower than that of CoQ10 $\left(\mathrm{EC}_{50}=88.35 \mu \mathrm{g} / \mathrm{ml}\right)$, which suggests that the P3G is twice stronger than CoQ10 as an antioxidant. Since the DPPH assay indirectly determines the presence of reactive hydroxyl groups on compounds, a higher scavenging activity suggests that P3G has more free hydroxyl groups than CoQ10, which is indeed consistent with its molecular structure [19]. However, this does not necessarily mean that CoQ10 is a poor antioxidant. Rather, the inferiority of CoQ10 with P3G and ascorbic acid may suggest that it demonstrates an antioxidant property via a different mechanism. Reports have shown that CoQ10 regenerates endogenous antioxidants and acts as free radical scavenger through autoreduction [20-22]. Further, the compound has been shown to increase the lifespan of $C$. elegans and various other organisms, which support its property as a strong antioxidant and its subsequent use as a positive control [11].

\section{P3G enhances the lifespan and healthspan of C. elegans}

Adult N2 C. elegans grown in our laboratory at $20^{\circ} \mathrm{C}$ has an average lifespan of 15 days. From the sublethal concentration of P3G at $50 \mu \mathrm{g} / \mathrm{ml}$, twofold dilutions $(25 \mu \mathrm{g} / \mathrm{ml}, 12.5 \mu \mathrm{g} / \mathrm{ml})$ were made to determine dose responses. For both 50 and $25 \mu \mathrm{g} / \mathrm{ml}$ P3G, the mean lifespan of $C$. elegans was extended by about 2.35 days $(+14 \%)$. Meanwhile, treatment with CoQ10 extended mean lifespan by 2.77 days $(+16 \%)$, which was comparable with P3G (Fig. 3(A,B) and Table S1). These findings were comparable with a report on crude blueberry and mulberry extracts, which showed a lengthening of the lifespan of C. elegans by $20 \%[3,4]$. While the effects of P3G in terms of lifespan extension was lower than that of the crude blueberry extracts, this pure anthocyanin was found to perform better than anthocyanins derived from purple wheat and acai, which extended the lifespan of $C$. elegans by only $11 \%$ and $5.6 \%$, respectively $[2,5]$. These suggest that pure peonidin alone can extend longevity in C. elegans, but other polyphenols are also seen contribute to lifespan extension. Variations in glucosidation patterns of peonidin may also contribute differing anthocyanin effects. Currently, no study has demonstrated the bioavailability of peonidin in humans. However, a recent study predicted the Absorption, Distribution, Metabolic, Excretion, and Transport (ADMET) property of peonidin following Lipinski's rule of five, which indicates high oral bioavailability [23]. Conversely, a human study involving anthocyanin-rich extracts detected $0.077 \%$ of anthocyanin in urine $4 \mathrm{~h}$ after the consumption, whereas the plasma concentration of anthocyanin is undetectable [24]. This evidence indicates that anthocyanin may have undergone conjugate formation after consumption, which still needs further investigation. Previous studies in humans also show 

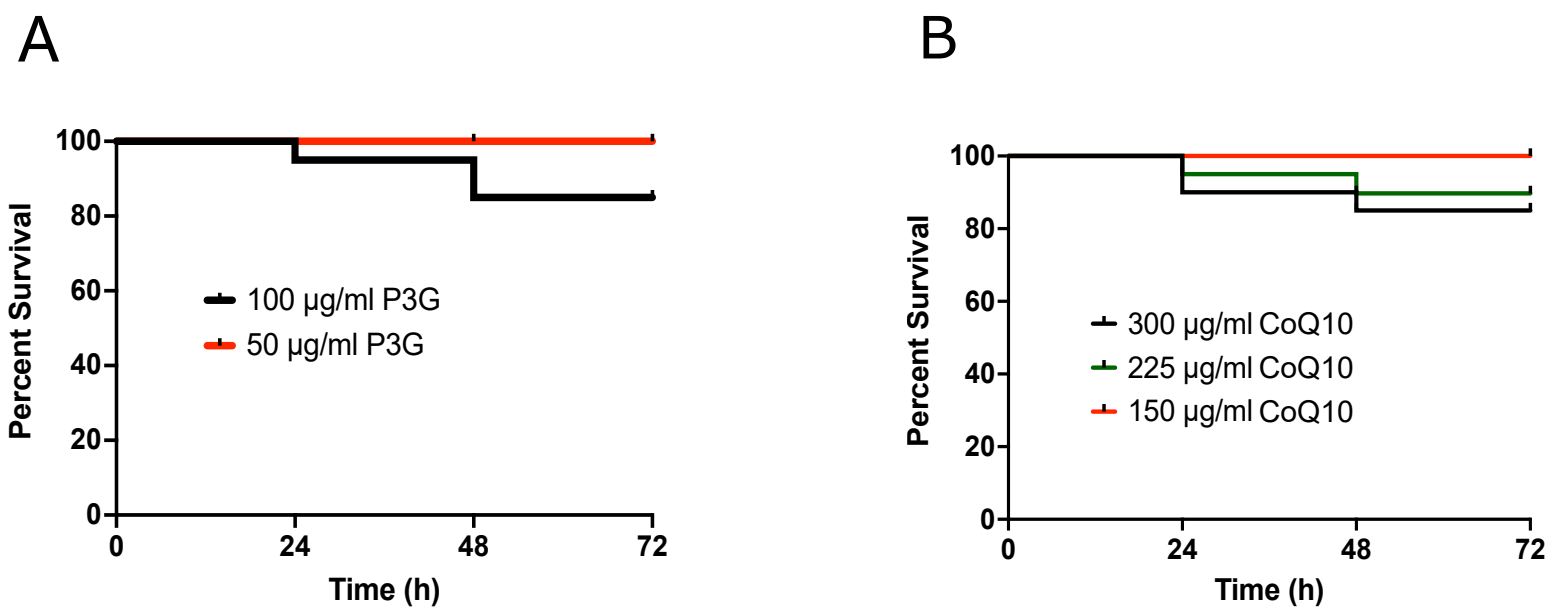

Fig. 1 Sublethal concentrations of peonidin-3-glucoside (P3G) and coenzyme Q10 after $72 \mathrm{~h}$. Thirty L4 stage nematodes on NGM treated with various concentrations of either P3G (A) or coenzyme Q10 (B).

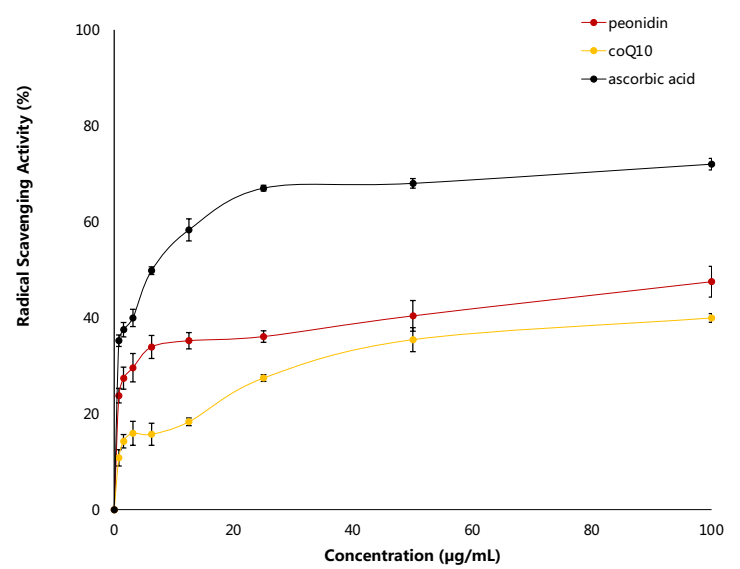

Fig. 2 Radical scavenging activity of ascorbic acid, peonidin-3-glucoside (P3G), and coenzyme Q10 (CoQ10) through DPPH assay.

that close to $50 \%$ of orally taken anthocyanins are absorbed through various routes, particularly $1 \%$ in oral cavities, $25 \%$ in stomach, and $11-22 \%$ in intestines [25, 26].

For nematodes fed with only OP50 E. coli and $\mathrm{dH}_{2} \mathrm{O}$, egg-laying was observed on the 1st day of adulthood and ended on the 7th day. Egg count was observed to spike on the 2nd day, which then immediately dropped on the 3rd day. This pattern was similarly observed in treatment groups exposed to varying concentrations of P3G and CoQ10. Apparently, all treatment groups showed no significant difference in the average eggs laid per nematode (Fig. 3(C,D) and Table S2) suggesting that P3G and CoQ10 may not be involved in the reproductive pathway or its eventual senescence in the C. elegans model. Interestingly, this egg-laying pattern was consistent with a previous report showing cessation of egg-laying at mid-adulthood of C. elegans [27]. Previous studies have also shown that DAF-12 plays a role in germline longevity $[28,29]$. In higher mammalian models, DAF-12 is activated by insulin peptides that would activate DAF-16 [5]. Through DAF-16, the TGF- $\beta$ pathway is activated, which leads to an arsenal of effects [30]. Compellingly, DAF-12 is conserved in C. elegans, and serves an elucidated purpose. During L2, exposure to stressors promotes transcription of genes for dauer formation [31]. Hence, DAF-12 is seen to increase stress tolerance, which ultimately leads to an increase in lifespan and healthspan. This study did not directly look into the effects of P3G on the transcript and protein levels of DAF-2, DAF-16, and DAF-12. However, previous studies have shown that anthocyanin-rich extracts, particularly containing P3G, affect DAF12, DAF-2, and DAF-16. In a previous study, mulberry extract upregulates DAF-12 protein [3]. Moreover, anthocyanin-rich purple wheat extract upregulates DAF-16 protein and suppresses DAF-2 protein, which favours longevity in the nematodes [2].

Since the dauer formation occurs only in L1L2 stage worms, it is possible that other pathways diverging from these genes are indeed present. Although DAF-12 and DAF-16 are known mediators in extending germline longevity, P3G was not able to affect reproduction and fertility. This might be due to the existence of secondary pathways involving in maintaining the integrity of the germline, where anthocyanin might not be involved in or might 

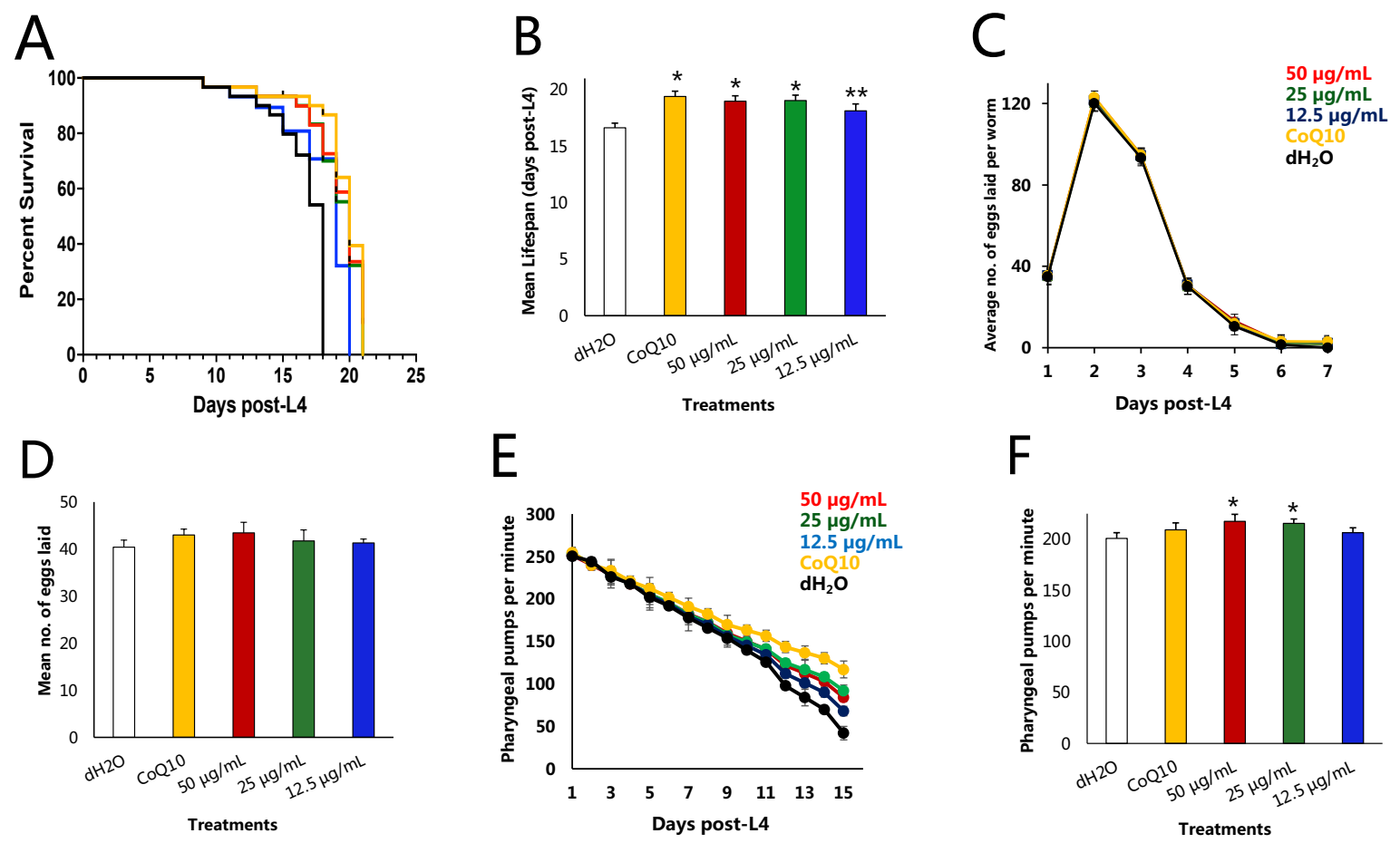

Fig. 3 Effects of P3G on lifespan, egg laying, and pharyngeal pumping in C. elegans without stress. Thirty L4 nematodes exposed to various concentrations (50, 25, and $12.5 \mu \mathrm{g} / \mathrm{ml}$ ) of P3G were observed for lifespan (A), mean lifespan (B), daily number of eggs laid (C), average number of eggs laid (D), daily pharyngeal pumping rate (E), and average pharyngeal pumping rate $(\mathrm{F})$. * denotes significance versus $\mathrm{dH}_{2} \mathrm{O}$ at $p<0.05$. ** denotes significance versus $\mathrm{dH}_{2} \mathrm{O}$ and CoQ10 at $p<0.05$.

only have a minimal effect. Alternatively, this may be part of a 'trade-off' between ensuring germline longevity and longevity of the nematode. Previous reports have shown the DAF-12 is required in C. elegans to extend lifespan in response to germline loss [32]. Hence, there must be a pathway that tips the balance in favour of either DAF-12 or DAF16 to better ensure the survival of $C$. elegans. Furthermore, inhibition of the DAF-2 pathway increases the lifespan of $C$. elegans by more than twofoldsuggesting the involvement of other pathways [2].

Similarly, P3G improved pharyngeal pumping rate of C. elegans by $8.3 \%$ and $7.3 \%$ at 50 and $25 \mu \mathrm{g} / \mathrm{ml}$, respectively which were non-significant compared with that of CoQ10 (Fig. 3(E,F) and Table S3). In a young adult $C$. elegans, the mean rate of pharyngeal pumping is about 250 pumps per min (ppm), which then declines as the worm naturally ages [33]. These suggest that P3G, at the sub-lethal concentration, can either increase food appetite or decrease smooth muscle degeneration comparable to that of CoQ10. This finding is consistent with its lifespan-extending effects and is probably re- lated to its antioxidant property. Therefore, this may be attributed to the retardation of age-related muscle deterioration. Damage repair pathways in aged muscle tissues are intuitively impaired. Thus, by potentially alleviating damage in myofilaments, through some mechanism probably involving DAF12, P3G can promote smooth muscle regeneration and the continued efficient functioning of the pharyngeal pumps.

During feeding, the requirement for ATP to sustain rapid smooth muscle contractions increases, which then leads to a higher respiration rate. Hence, higher reactive oxygen species (ROS) production brought about by increased oxidative phosphorylation increases cellular oxidative stress [34]. The protective effects of P3G on pharyngeal pumping rate, which was evident in unexposed worms and to those exposed to various stressors, suggest a possible mechanism retarding age-associated degeneration of nematode smooth muscles. Since both P3G and CoQ10 were able to retard the decline in pharyngeal pumping rate over time with nearly comparable effects, this protective function of P3G 
may be strongly related to its antioxidant property. Furthermore, the behaviour of the pharyngeal neurons is dependent on various neurotransmitters such as GABA, serotonin, dopamine, glutamate, acetylcholine, and neuropeptides [35]. Accordingly, it is also possible that P3G or CoQ10 activates pathways that release these neurotransmitters locally in the C. elegans pharynx and gut, which may promote further pharyngeal pumping.

\section{Heat stress assay}

When exposed to daily heat $\left(30^{\circ} \mathrm{C}\right)$ for $30 \mathrm{~min}$, nematodes exposed to $\mathrm{dH}_{2} \mathrm{O}$ had their lifespan shortened by about 7 days $(-42 \%)$. Of the three concentrations of P3G, only $50 \mu \mathrm{g} / \mathrm{ml}$ extended lifespan in the presence of heat, increasing it by 2.2 days $(+23 \%)$ from the baseline $\mathrm{dH}_{2} \mathrm{O}$ group (Fig. 4(A,B) and Table S4). However, this increase in lifespan was not sufficient to return $C$. elegans lifespan back to normal. Meanwhile, CoQ10 did not improve longevity and was non-significant compared with $\mathrm{dH}_{2} \mathrm{O}$. The observed lifespan increase by P3G is consistent with studies showing anthocyaninrelated increases in lifespan in the presence of heat stress, which suggest possible mechanisms promoting thermotolerance [4]. Regardless of the mechanism, pure P3G lengthened the lifespan of $C$. elegans exposed to chronic, daily heat stress.

In terms of healthspan, egg-laying ability and pharyngeal pumping rates of those exposed to daily heat stress declined significantly compared with unexposed worms. In general, the number of days C. elegans observed to lay eggs decreased by 1 day when exposed to heat stress. However, a similar trend was preserved where number of eggs spiked on the 2nd day and immediately dropped on the 3rd day. In terms of the mean number of eggs laid per day, no significant differences were observed in P3G and CoQ10 compared with $\mathrm{dH}_{2} \mathrm{O}$ (Fig. 4(C,D) and Table S5), suggesting that neither P3G nor CoQ10 significantly affected reproduction and fertility under heat stress, which was consistent with previous study results.

A faster decline in pharyngeal pumping rate was also observed in the $\mathrm{dH}_{2} \mathrm{O}$ group, where a decrease of about 50 pumps/min was observed by day 9 compared with unexposed worms. Treatment with CoQ10 or P3G attenuated this decline; however, the mean pharyngeal pumping rate remained nonsignificant between all treatment groups, suggesting that P3G or CoQ10 may slow down the rate but cannot prevent absolute pumping rate decline (Fig. 4(E,F) and Table S6).
As shown in Fig. 4(A,B), only P3G extended the lifespan of $C$. elegans under chronic heat stress. Furthermore, this increase in lifespan is not associated with an improvement in healthspan, since neither P3G nor CoQ10 was able to rescue pharyngeal pumping compared with $\mathrm{dH}_{2} \mathrm{O}$ (Fig. 4F). Upon comparing lifespan and healthspan during heat stress, no observable trend was found. This only implies that another factor, which is still unknown, might have influenced the physiological response of the worm and the effects of P3G during heat stress. Previous studies on blueberry, cranberry, and purple wheat extracts demonstrated variable extensions in the lifespan of $C$. elegans $[2,4]$. These effects may be a function of the individual capabilities of the anthocyanins to reduce heat-induced oxidative stress, or of differences in thermotolerance due to other polyphenols in the crude extracts [4]. Notwithstanding, our data on heat stress suggests that P3G protects C. elegans from chronic heat through mechanisms independent of its free radical scavenging ability.

\section{UV stress assay}

Nematodes exposed to UVA radiation daily for 3 min showed a reduction in lifespan by 8.03 days $(-48 \%)$, which was far greater than that seen under heat stress. Nematodes concomitantly exposed to $50 \mu \mathrm{g} / \mathrm{ml}$ P3G extended their lifespan by 2.1 days (+25\%) compared with $\mathrm{dH}_{2} \mathrm{O}$, which was not evident in the CoQ10 group (Fig. 5(A,B) and Table S7). This suggests that antioxidant properties may play minor roles in reducing the effects of photoaging, which points to mechanisms possibly employed by P3G and independent of free radical scavenging.

UVA radiation decreased the number of eggs laid by C. elegans by $21 \%$. However, as with heat stress, the same pattern was observed where egg laying peaked on day 2 of adulthood. Comparison of the mean number of eggs laid per worm showed that all treatments demonstrated similar trends with that of the $\mathrm{dH}_{2} \mathrm{O}$ group, which is consistent with findings demonstrating its lack of efficacy in reproduction and fertility (Fig. 5(C,D) and Table S8).

Interestingly, pharyngeal pumping rate showed a much steeper decline over time in the $\mathrm{dH}_{2} \mathrm{O}$ group, even if $\mathrm{UV}$ radiation is not expected to directly affect internal structures. The different concentrations of P3G $(50,25 \mu \mathrm{g} / \mathrm{ml})$ showed minor improvements in pharyngeal pumping rate, which was comparable to that of the CoQ10 group (Fig. 5(E,F) and Table S9). In summary, mean pharyngeal pumping rates increased with $50 \mu \mathrm{g} / \mathrm{ml}$ P3G by $6.2 \%$ and CoQ10 by 

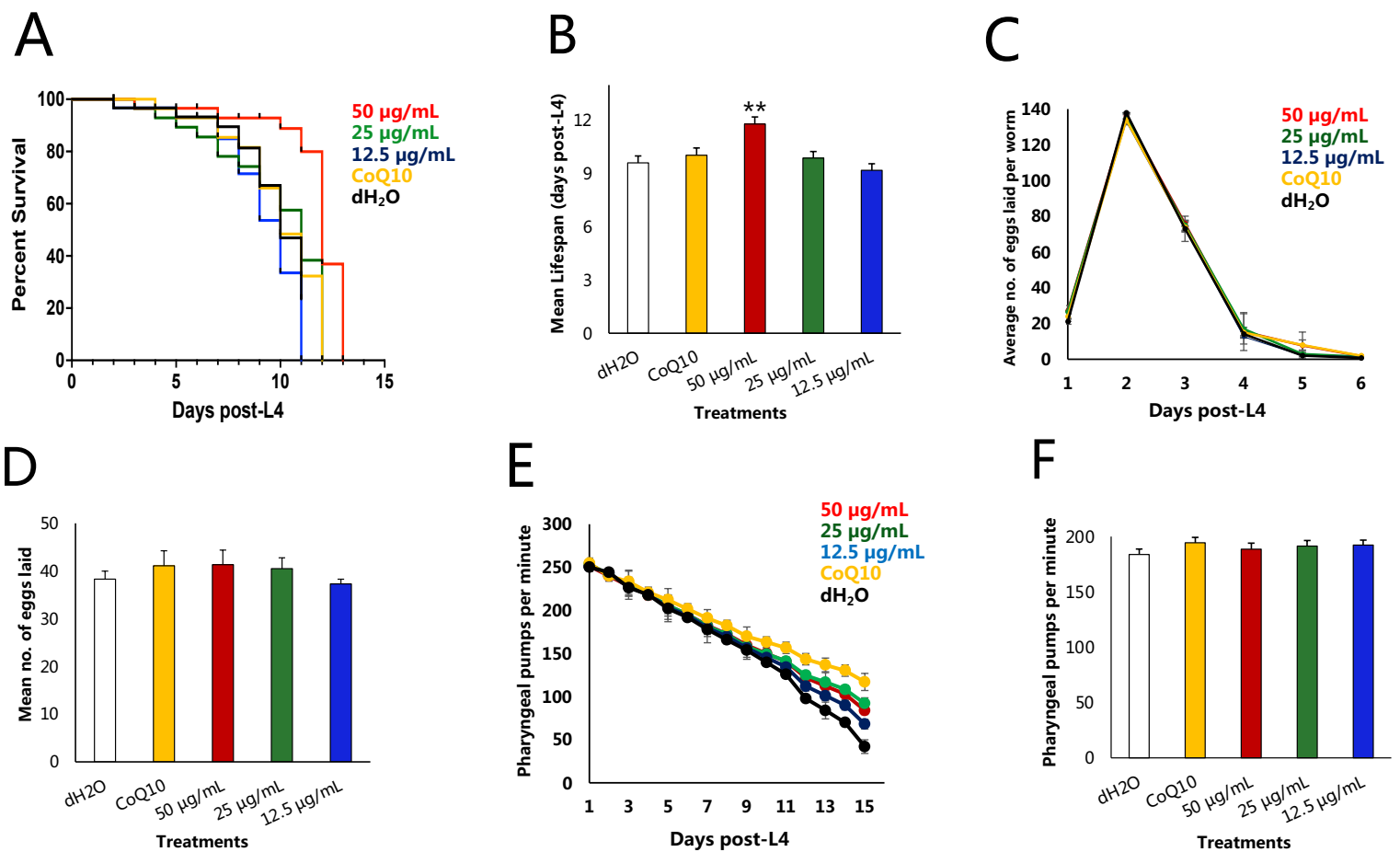

Fig. 4 Effects of P3G on lifespan, egg laying, and pharyngeal pumping in C. elegans under heat stress. Thirty L4 nematodes fed with various concentrations $(50,25$, and $12.5 \mu \mathrm{g} / \mathrm{ml})$ of P3G were exposed to heat stress. The following parameters were observed: daily lifespan (A), mean lifespan (B), daily number of eggs laid (C), average number of eggs laid (D), daily pharyngeal pumping rate (E), and average pharyngeal pumping rate (F). * denotes significance versus $\mathrm{dH}_{2} \mathrm{O}$ at $p<0.05$. ** denotes significance versus $\mathrm{dH}_{2} \mathrm{O}$ and CoQ10 at $p<0.05$.

9.7\% relative to the negative control ( $p<0.05)$.

Since the mean lifespan of the $\mathrm{dH}_{2} \mathrm{O}$ C. elegans significantly decreased, this suggests that photoaging accelerates senescence or cell death in the nematode model. Some studies have shown that UV radiation damages the DNA of C. elegans by inducing cyclobutene dimers and pyrimidine photoproducts [36]. An excess of these reactions may in fact explain the decrease in the mean lifespan despite the existence of a DNA repair system [37]. In this study, only P3G was able to prolong the lifespan of $C$. elegans significantly. In contrast, a recent study showed that other anthocyanin extracts were not able to extend the lifespan of $C$. elegans when exposed to UV [6]. Currently, there are no sufficient data in the literature that can identify the mechanism of action of P3G in response to UV stress; however, an eventual daf-16 gene mutation may be able to subdue UV resistance [38]. Accordingly, rad genes, particularly rad-1, rad-2, xpa-1, and rad-7, are found to be involved in the UV-induced stress responses [39]. Importantly, xpa-1, previously known as rad-3, is important in removing UV- induced pyrimidine dimers [34]. Induction of the stress response may lead to cell senescence and the activation of unfolded protein responses in cells directly affected by UV radiation in an effort to salvage the cells-which may result to either cell regeneration or a commitment to cell death [40]. However, there remains no evidence to support that anthocyanin influences xpa-1 along with its downstream target. Thus, so far, P3G is only suspected to lessen the consequences of oxidative damages as well as DNA strand breaks or dimer formation induced by UVA.

\section{Oxidative stress assay}

The lifespan of $C$. elegans was strongly affected by oxidative stress as observed by a significant decrease of 8.49 days $(-51 \%)$. However, treatment with $50 \mu \mathrm{g} / \mathrm{ml}$ P3G lengthened lifespan by 3.81 days $(+47 \%)$ compared with the untreated group ( $p<$ 0.05), as shown in Fig. 6(A,B) and Table S10.

Under oxidative stress, egg laying in C. elegans was observed to have diminished by about $25 \%$ on a daily average compared with $C$. elegans not exposed to stress $(p<0.05)$. However, the same 
A

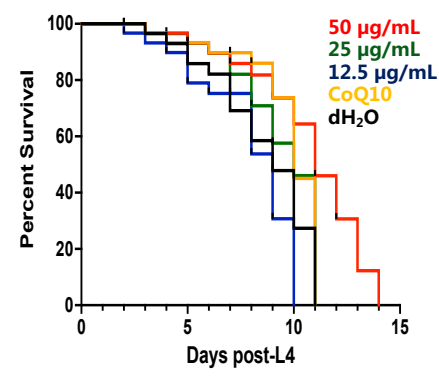

D

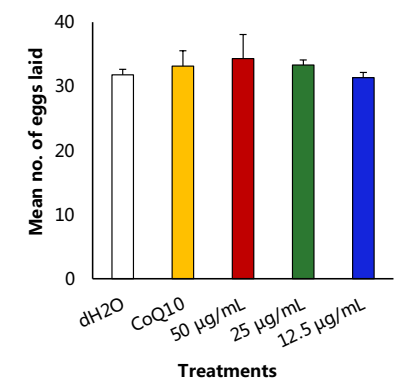

B

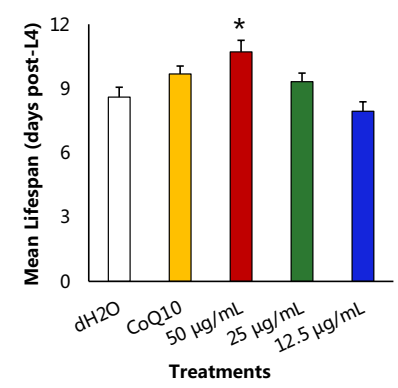

E

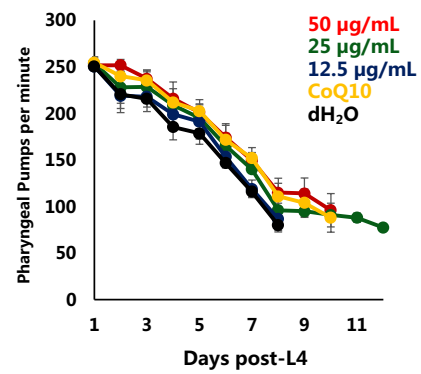

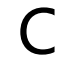

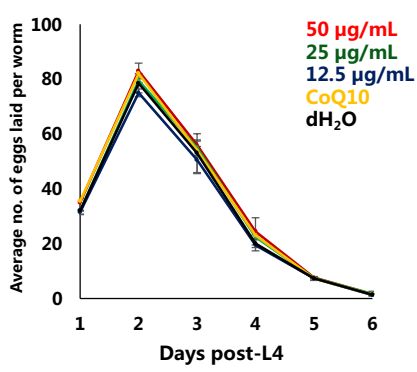

$\mathrm{F}$

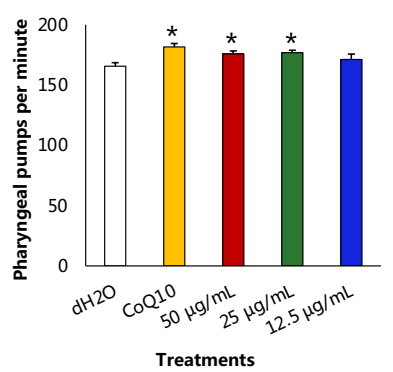

Fig. 5 Effects of P3G on lifespan, egg laying, and pharyngeal pumping in C. elegans under UVA stress. Thirty L4 nematodes fed with various concentrations $(50,25$, and $12.5 \mu \mathrm{g} / \mathrm{ml})$ of P3G were exposed to UVA stress. The following parameters were observed: daily lifespan (A), mean lifespan (B), daily number of eggs laid (C), average number of eggs laid (D), daily pharyngeal pumping rate (E), and average pharyngeal pumping rate (F). * denotes significance versus $\mathrm{dH}_{2} \mathrm{O}$ at $p<0.05$. ** denotes significance versus $\mathrm{dH}_{2} \mathrm{O}$ and CoQ10 at $p<0.05$.

trend was observed with the heat and UV stress setups, where the number of eggs spiked on the 2nd day and immediately dropped on the 3rd day. Mean number of eggs laid in treatments with varying concentrations of P3G, CoQ10, and $\mathrm{dH}_{2} \mathrm{O}$ were all comparable (Fig. 6(C,D) and Table S11).

Direct head exposure to $\mathrm{H}_{2} \mathrm{O}_{2}$ also negatively affected the healthspan of the nematode, as suggested by the drastic decline in its pharyngeal pumping rate within a short period of time. Concomitant treatments with CoQ10 and P3G significantly attenuated the rapid decrease of pharyngeal pumping rate (Fig. 6(E,F) and Table S12), with P3G $(50 \mu \mathrm{g} / \mathrm{ml})$ having the most significant increase by $19.8 \%$, followed by CoQ10 and $25 \mu \mathrm{g} / \mathrm{ml}$ P3G by about $17 \%$ and $11 \%$, respectively $(p<0.05)$.

What is important to note is that the concentration of $\mathrm{H}_{2} \mathrm{O}_{2}(100 \mu \mathrm{M})$ given to the worms did not result to acute lethality. Some worms were able to survive up to day 10 of adulthood, which suggests that the oxidative damage was only able to hasten aging but was not sufficient to kill the nematodes outright. This is significant in preventing the under- estimation of the in vivo antioxidant potential of P3G brought about by acute lethality. These results are by far consistent with previous studies on mulberry and acai berry, which demonstrate that anthocyanin extracts prolong the lifespan of $C$. elegans under oxidative stress $[3,5]$.

\section{CONCLUSION}

In this study, we showed that peonidin-3-glucoside (P3G) was a stronger hydroxyl-containing antioxidant than CoQ10, with a twofold lower EC $_{50}$ in the DPPH assay. We also showed that in the absence of stressors, P3G was able to extend C. elegans lifespan by $14 \%$ as well as pharyngeal pumping rate by $8.3 \%$, which indicate improvements in both lifespan and healthspan. In the presence of stresses, P3G showed optimal protection from $\mathrm{H}_{2} \mathrm{O}_{2}$, increasing lifespan by up to $47 \%$ and pharyngeal pumping rate by $19.8 \%$ compared with vehicle, as opposed to heat stress which showed a benefit of only $23 \%$ in lifespan. Likewise, CoQ10 was able to comparably extend C. elegans lifespan by about $16 \%$ in the absence of stresses but was only able to benefit the nematode 
A

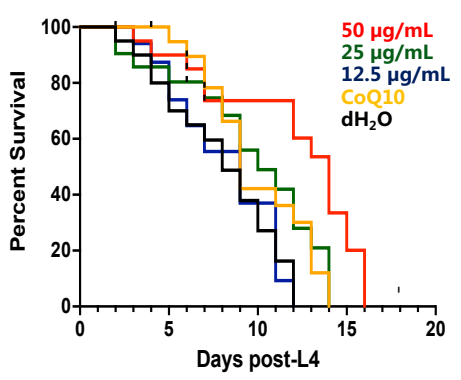

D

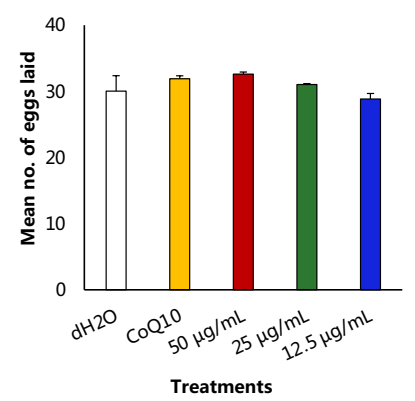

B

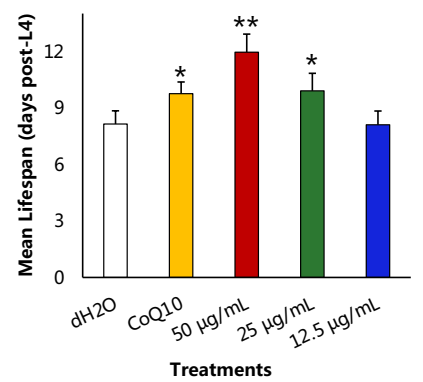

$E$

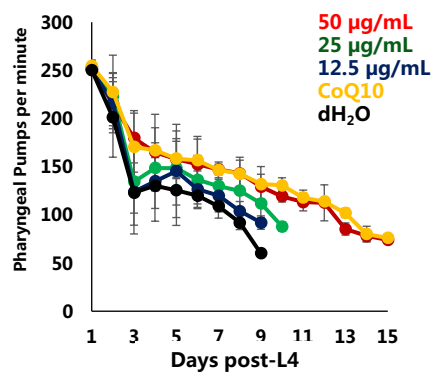

C

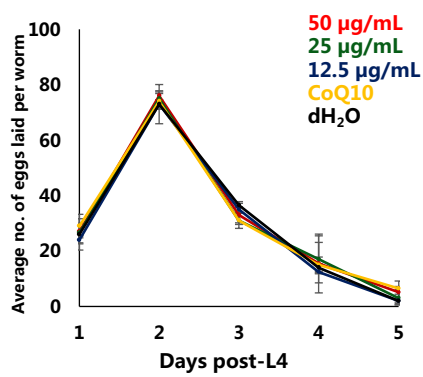

$\mathrm{F}$

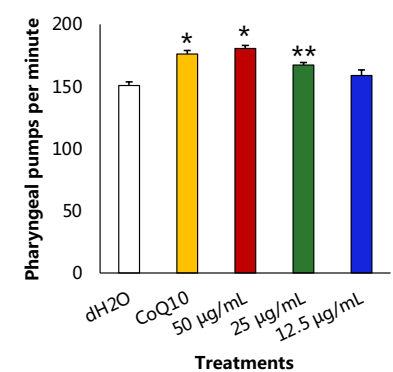

Fig. 6 Effects of P3G on lifespan, egg laying, and pharyngeal pumping in C. elegans under oxidative stress. Thirty L4 nematodes fed with various concentrations $(50,25$, and $12.5 \mu \mathrm{g} / \mathrm{ml}$ ) of P3G were exposed to oxidative stress. The following parameters were observed: daily lifespan (A), mean lifespan (B), daily number of eggs laid (C), average number of eggs laid (D), daily pharyngeal pumping rate (E), and average pharyngeal pumping rate (F). * denotes significance versus $\mathrm{dH}_{2} \mathrm{O}$ at $p<0.05$. ** denotes significance versus $\mathrm{dH}_{2} \mathrm{O}$ and CoQ10 at $p<0.05$.

significantly under oxidative stress. In contrast, neither P3G nor CoQ10 was able to significantly affect egg-laying ability. Taken together, we show that P3G is an efficacious compound in increasing both lifespan and healthspan of $C$. elegans, which supports previous reports of anthocyanin benefits in the nematode model. These results must be clarified in higher animal models for external validity and warrant further investigation, especially on their non-antioxidant mechanisms of action.

\section{Appendix A. Supplementary data}

Supplementary data associated with this article can be found at http://dx.doi.org/10.2306/ scienceasia1513-1874.2021.059.

Acknowledgements: This work was supported by the Department of Science and Technology-Science Education Institute (DOST-SEI), which provided the means to procure reagents, strains, and consumable materials. Furthermore, strains were obtained from and provided by the Caenorhabditis Genetics Center (CGC) of the University of Minnesota, which is funded by the NIH Office of Research
Infrastructure Programs (P40 OD010440). We would also like to thank Jozelle B. Ponce, MSc for providing shipping assistance and voluntary maintenance of $C$. elegans.

\section{REFERENCES}

1. He JJ, Liu YX, Pan QH, Cui XY, Duan CQ (2010) Different anthocyanin profiles of the skin and the pulp of Yan73 (Muscat Hamburg $\times$ Alicante Bouschet) grape berries. Molecules 15, 1141-1153.

2. Chen W, Müller D, Richling E, Wink M (2013) Anthocyanin-rich purple wheat prolongs the lifespan of Caenorhabditis elegans probably by activating the DAF-16/FOXO transcription factor. J Agri Food Chem 61, 3047-3053.

3. Zheng S, Liao S, Zou Y, Qu Z, Shen W, Shi Y (2014) Mulberry leaf polyphenols delay aging and regulate fat metabolism via the germline signaling pathway in Caenorhabditis elegans. Age 36, ID 9719.

4. Wilson MA, Shukitt-Hale B, Kalt W, Ingram DK, Joseph JA, Wolkow CA (2006) Blueberry polyphenols increase lifespan and thermotolerance in Caenorhabditis elegans. Aging Cell 5, 59-68.

5. Peixoto H, Roxo M, Krstin S, Röhrig T, Richling E, Wink M (2016) An anthocyanin-rich extract of acai 
(Euterpe precatoria Mart.) increases stress resistance and retards aging-related markers in Caenorhabditis elegans. J Agri Food Chem 64, 1283-1290.

6. Guha S, Cao M, Kane RM, Savino AM, Zou S, Dong Y (2013) The longevity effect of cranberry extract in Caenorhabditis elegans is modulated by daf-16 and osr-1. Age 35, 1559-1574.

7. Pérez-Gregorio RM, García-Falcón MS, SimalGándara J, Rodrigues AS, Almeida DP (2010) Identification and quantification of flavonoids in traditional cultivars of red and white onions at harvest. J Food Compos Anal 23, 592-598.

8. Ahmadiani N, Robbins RJ, Collins TM, Giusti MM (2014) Anthocyanin contents, profiles, and color characteristics of red cabbage extracts from different cultivars and maturity stages. J Agri Food Chem 62, 7524-7531.

9. Moriya C, Hosoya T, Agawa S, Sugiyama Y, Kozone I, Shin-Ya K, Terahara N, Kumazawa S (2015) New acylated anthocyanins from purple yam and their antioxidant activity. Biosci Biotechnol Biochem 79, 1484-1492.

10. Kangwan N, Pintha K, Preedapirom W, Tantipaiboonwong P, Chumphukam O, Suttajit M (2015) Learning and memory enhancing effects of anthocyanin in black rice extract on cerebral ischaemia in mice. ScienceAsia 41, 315-321.

11. Ishii N, Senoo-Matsuda N, Miyake K, Yasuda K, Ishii T, Hartman PS, Furukawa S (2004) Coenzyme Q10 can prolong $C$. elegans lifespan by lowering oxidative stress. Mech Ageing Dev 125, 41-46.

12. Manalo RVM, Medina PMB (2018) Caffeine protects dopaminergic neurons from dopamine-induced neurodegeneration via synergistic adenosinedopamine D2-like receptor interactions in transgenic Caenorhabditis elegans. Front Neurosci 12, ID 137.

13. Fitzenberger E, Deusing DJ, Wittkop A, Kler A, Kriesl E, Bonnländer B, Wenzel U (2014) Effects of plant extracts on the reversal of glucose-induced impairment of stress-resistance in Caenorhabditis elegans. Plant Foods Hum Nutri 69, 78-84.

14. Park H-EH, Jung Y, Lee S-JV (2017) Survival assays using Caenorhabditis elegans. Mol Cells 40, 90-99.

15. Raizen D, Song BM, Trojanowski N, You YJ (2012) Methods for measuring pharyngeal behaviors. Wormbook 18, 1-13.

16. Bhatla N, Horvitz HR (2015) Light and hydrogen peroxide inhibit $C$. elegans feeding through gustatory receptor orthologs and pharyngeal neurons. Neuron 85, 804-818.

17. Saiki R, Lunceford AL, Bixler T, Dang P, Lee W, Furukawa S, Larsen PL, Clarke CF (2008) Altered bacterial metabolism, not coenzyme Q content, is responsible for the lifespan extension in Caenorhabditis elegans fed an Escherichia coli diet lacking coenzyme Q. Aging Cell 7, 291-304.

18. Gomez F, Saiki R, Chin R, Srinivasan C, Clarke CF
(2012) Restoring de novo Coenzyme Q biosynthesis in Caenorhabditis elegans coq-3 mutants yields profound rescue compared to exogenous Coenzyme Q supplementation. Gene 506, 106-116.

19. Kähkönen MP, Heinonen M (2003) Antioxidant activity of anthocyanins and their aglycons. J Agri Food Chem 51, 628-633.

20. Geng AL, Guo YM, Yang Y (2004) Reduction of ascites mortality in broilers by coenzyme Q10. Poultry Sci 83, 1587-1593.

21. Santos-González M, Díaz CG, Navas P, Villalba JM (2007) Modifications of plasma proteome in longlived rats fed on a coenzyme Q10-supplemented diet. Exp Geront 42, 798-806.

22. Tang PH, Miles MV, DeGrauw A, Hershey A, Pesce A (2001) HPLC analysis of reduced and oxidized coenzyme Q10 in human plasma. Clin Chem 47, 256-265.

23. Nas JS (2020) Exploring the binding affinity and non-covalent interactions of anthocyanins with aging-related enzymes through molecular docking. Phil J Health Res Dev 24, 9-19.

24. Wu X, Cao G, Prior RL (2002) Absorption and metabolism of anthocyanins in elderly women after consumption of elderberry or blueberry. J Nutr 132, 1865-1871.

25. Talavera S, Felgines C, Texier O, Besson C, Manach C, Lamaison JL, Rémésy C (2004) Anthocyanins are efficiently absorbed from the small intestine in rats. J Nutr 134, 2275-2279.

26. Fernandes I, Faria A, Calhau C, de Freitas V, Mateus N (2014) Bioavailability of anthocyanins and derivatives. J Funct Foods 7, 54-66.

27. Singson A, Hang JS, Parry JM (2004) Genes required for the common miracle of fertilization in Caenorhabditis elegans. Int $J$ Dev Bio 52, 647-656.

28. Hansen M, Hsu AL, Dillin A, Kenyon C (2005) New genes ted to endocrine, metabolic, and dietary regulation of lifespan from a Caenorhabditis elegans genomic RNAi screen. PLoS Genet 1, ID 10017.

29. Berman JR, Kenyon C (2006) Germ-cell loss extends C. elegans life span through regulation of DAF-16 by kri-1 and lipophilic-hormone signaling. Cell 124, 1055-1068.

30. Magner DB, Antebi A (2008) Caenorhabditis elegans nuclear receptors: insights into life traits. Trend Endoc Metab 19, 153-160.

31. Antebi A (2013) Regulation of longevity by the reproductive system. Exp Geront 48, 596-602.

32. Sun X, Chen WD, Wang YD (2017) DAF-16/FOXO transcription factor in aging and longevity. Front Pharmacol 8, ID 548.

33. Chow DK, Glenn CF, Johnston JL, Goldberg IG, Wolkow CA (2006) Sarcopenia in the Caenorhabditis elegans pharynx correlates with muscle contraction rate over lifespan. Exp Gerontol 41, 252-260.

34. Turrens JF (2003) Mitochondrial formation of reac- 
tive oxygen species. $J$ Physiol 552, 335-344.

35. Bansal A, Zhu LJ, Yen K, Tissenbaum HA (2015) Uncoupling lifespan and healthspan in Caenorhabditis elegans longevity mutants. Proc Natl Acad Sci USA 112, E277-E286.

36. Hartman PS, Hevelone J, Dwarakanath V, Mitchell DL (1989) Excision repair of UV radiation-induced DNA damage in Caenorhabditits elegans. Genetics 122, 379-385.

37. Coohill T, Marshall T, Schubert W, Nelson G (1988) Ultraviolet mutagenesis of radiation-sensitive (rad) mutants of the nematode Caenorhabditis elegans. Mut
Res Lett 209, 99-106.

38. Murakami S, Johnson TE (1996) A genetic pathway conferring life extension and resistance to UV stress in Caenorhabditis elegans. Genetics 143, 1207-1218.

39. Stewart HI, Rosenbluth RE, Baillie DL (1991) Most ultraviolet irradiation induced mutations in the nematode Caenorhabditis elegans are chromosomal rearrangements. Mut Res 249, 37-54.

40. Manalo RVM, Medina PMB (2018) The endoplasmic reticulum stress response in disease pathogenesis and pathophysiology. Egypt J Med Hum Genet 19, 59-68. 


\section{Appendix A. Supplementary data}

Table S1 Effects of P3G on the lifespan of C. elegans in the absence of stresses.

\begin{tabular}{lrrr}
\hline Treatment & Mean \pm SE & Comparison & $p$-value \\
\hline $\mathrm{dH}_{2} \mathrm{O}$ & $16.63 \pm 0.41$ & & $<0.0001$ \\
$\mathrm{CoQ} 10$ & $19.4 \pm 0.47$ & $\mathrm{dH}_{2} \mathrm{O}$ & 0.0327 \\
$12.5 \mu \mathrm{g} / \mathrm{ml} \mathrm{P3G}$ & $18.13 \pm 0.61$ & $\mathrm{dH}_{2} \mathrm{O}$ & 0.0367 \\
& & $\mathrm{CoQ} 10$ & 0.0009 \\
$25 \mu \mathrm{g} / \mathrm{ml} \mathrm{P3G}$ & $19.04 \pm 0.48$ & $\mathrm{dH} \mathrm{H}_{2} \mathrm{O}$ & 0.6933 \\
& & $\mathrm{CoQ}_{10}$ & 0.0011 \\
$50 \mu \mathrm{g} / \mathrm{ml} \mathrm{P3G}$ & $18.98 \pm 0.48$ & $\mathrm{dH}_{2} \mathrm{O}$ & 0.3707 \\
& & $\mathrm{CoQ}_{10}$ & \\
\hline
\end{tabular}

Table S2 Effects of P3G on the egg laying of C. elegans in the absence of stresses.

\begin{tabular}{|c|c|c|c|}
\hline Treatment & Mean \pm SD & Comparison & $p$-value \\
\hline $\mathrm{dH}_{2} \mathrm{O}$ & $40.41 \pm 1.502$ & & \\
\hline CoQ10 & $43.00 \pm 1.249$ & $\mathrm{dH} 2 \mathrm{O}$ & 0.9700 \\
\hline \multirow[t]{2}{*}{$12.5 \mu \mathrm{g} / \mathrm{ml} \mathrm{P3G}$} & $41.31 \pm 0.826$ & $\mathrm{dH}_{2} \mathrm{O}$ & $>0.9999$ \\
\hline & & CoQ10 & 0.9947 \\
\hline \multirow[t]{2}{*}{$25 \mu \mathrm{g} / \mathrm{ml}$ P3G } & $41.74 \pm 2.336$ & $\mathrm{dH}_{2} \mathrm{O}$ & $>0.9999$ \\
\hline & & CoQ10 & $>0.9999$ \\
\hline \multirow[t]{2}{*}{$50 \mu \mathrm{g} / \mathrm{ml} \mathrm{P3G}$} & $43.45 \pm 2.244$ & $\mathrm{dH}_{2} \mathrm{O}$ & 0.9700 \\
\hline & & CoQ10 & 0.9861 \\
\hline
\end{tabular}

Table S3 Effects of P3G on the pharyngeal pumping of C. elegans in the absence of stresses.

\begin{tabular}{lccr}
\hline Treatment & Mean \pm SD & Comparison & $p$-value \\
\hline $\mathrm{dH} 2 \mathrm{O}$ & $200.8 \pm 5.6$ & & \\
$\mathrm{CoQ} 10$ & $209.2 \pm 6.8$ & $\mathrm{dH} 2 \mathrm{O}$ & 0.6006 \\
$12.5 \mu \mathrm{g} / \mathrm{ml} \mathrm{P3G}$ & $206.4 \pm 4.8$ & $\mathrm{dH}_{2} \mathrm{O}$ & 0.9459 \\
& & $\mathrm{CoQ} 10$ & 0.9998 \\
$25 \mu \mathrm{g} / \mathrm{ml} \mathrm{P3G}$ & $215.5 \pm 4.3$ & $\mathrm{dH} O$ & 0.0015 \\
& & $\mathrm{CoQ}_{2} \mathrm{O}$ & 0.6768 \\
$50 \mu \mathrm{g} / \mathrm{ml} \mathrm{P3G}$ & $217.5 \pm 6.9$ & $\mathrm{dH}_{2} \mathrm{O}$ & 0.0002 \\
& & $\mathrm{CoQ}_{10}$ & 0.5964 \\
\hline
\end{tabular}

Table S4 Effects of P3G on the lifespan of C. elegans under heat stress.

\begin{tabular}{lrcr}
\hline Treatment & Mean \pm SE & Comparison & $p$-value \\
\hline $\mathrm{dH}_{2} \mathrm{O}$ & $9.61 \pm 0.39$ & & \\
$\mathrm{CoQ} 10$ & $10.04 \pm 0.41$ & $\mathrm{dH}_{2} \mathrm{O}$ & 0.7098 \\
$12.5 \mu \mathrm{g} / \mathrm{ml} \mathrm{P3G}$ & $9.19 \pm 0.40$ & $\mathrm{dH}_{2} \mathrm{O}$ & 0.2009 \\
& & $\mathrm{CoQ} 10$ & 0.0859 \\
$25 \mu \mathrm{g} / \mathrm{ml} \mathrm{P3G}$ & $9.88 \pm 0.37$ & $\mathrm{dH} O$ & 0.5992 \\
& & $\mathrm{CoQ} 10$ & 0.7958 \\
$50 \mu \mathrm{g} / \mathrm{ml} \mathrm{P3G}$ & $11.8 \pm 0.37$ & $\mathrm{dH}_{2} \mathrm{O}$ & 0.0005 \\
& & $\mathrm{CoQ} 10$ & 0.0005 \\
\hline
\end{tabular}


Table S5 Effects of P3G on the egg laying of C. elegans under heat stress.

\begin{tabular}{|c|c|c|c|}
\hline Treatment & Mean \pm SD & Comparison & $p$-value \\
\hline $\mathrm{dH}_{2} \mathrm{O}$ & $38.3 \pm 1.68$ & & \\
\hline CoQ10 & $41.1 \pm 3.14$ & $\mathrm{dH}_{2} \mathrm{O}$ & 0.9984 \\
\hline \multirow[t]{2}{*}{$12.5 \mu \mathrm{g} / \mathrm{ml} \mathrm{P3G}$} & $37.3 \pm 0.99$ & $\mathrm{dH}_{2} \mathrm{O}$ & $>0.9999$ \\
\hline & & CoQ10 & 0.9291 \\
\hline \multirow[t]{2}{*}{$25 \mu \mathrm{g} / \mathrm{ml}$ P3G } & $40.5 \pm 2.27$ & $\mathrm{dH}_{2} \mathrm{O}$ & $>0.9999$ \\
\hline & & CoQ10 & 0.9997 \\
\hline \multirow[t]{2}{*}{$50 \mu \mathrm{g} / \mathrm{ml}$ P3G } & $41.3 \pm 3.06$ & $\mathrm{dH}_{2} \mathrm{O}$ & $>0.9999$ \\
\hline & & CoQ10 & $>0.9999$ \\
\hline
\end{tabular}

Table S6 Effects of P3G on the pharyngeal pumping of $C$. elegans under heat stress.

\begin{tabular}{|c|c|c|c|}
\hline Treatment & Mean \pm SD & Comparison & $p$-value \\
\hline $\mathrm{dH}_{2} \mathrm{O}$ & $183.8 \pm 4.941$ & & \\
\hline CoQ10 & $194.4 \pm 4.859$ & $\mathrm{dH}_{2} \mathrm{O}$ & 0.5470 \\
\hline \multirow[t]{2}{*}{$12.5 \mu \mathrm{g} / \mathrm{ml} \mathrm{P3G}$} & $192.3 \pm 4.486$ & $\mathrm{dH}_{2} \mathrm{O}$ & 0.9133 \\
\hline & & CoQ10 & $>0.9999$ \\
\hline \multirow[t]{2}{*}{$25 \mu \mathrm{g} / \mathrm{ml}$ P3G } & $191.4 \pm 5.037$ & $\mathrm{dH}_{2} \mathrm{O}$ & 0.8985 \\
\hline & & CoQ10 & $>0.9999$ \\
\hline \multirow[t]{2}{*}{$50 \mu \mathrm{g} / \mathrm{ml}$ P3G } & $188.6 \pm 5.445$ & $\mathrm{dH}_{2} \mathrm{O}$ & 0.9974 \\
\hline & & CoQ10 & 0.9815 \\
\hline
\end{tabular}

Table S7 Effects of P3G on the lifespan of C. elegans under UV stress.

\begin{tabular}{lccr}
\hline Treatment & Mean \pm SE & Comparison & $p$-value \\
\hline $\mathrm{dH}_{2} \mathrm{O}$ & $8.60 \pm 0.46$ & & \\
$\mathrm{CoQ} 10$ & $9.68 \pm 0.37$ & $\mathrm{dH}_{2} \mathrm{O}$ & 0.0518 \\
$12.5 \mu \mathrm{g} / \mathrm{ml} \mathrm{P3G}$ & $7.94 \pm 0.44$ & $\mathrm{dH}_{2} \mathrm{O}$ & 0.9261 \\
& & $\mathrm{CoQ}_{10}$ & 0.0346 \\
$25 \mu \mathrm{g} / \mathrm{ml} \mathrm{P3G}$ & $9.32 \pm 0.40$ & $\mathrm{dH}_{2} \mathrm{O}$ & 0.2332 \\
& & $\mathrm{CoQ}_{10}$ & 0.4236 \\
$50 \mu \mathrm{g} / \mathrm{ml} \mathrm{P3G}$ & $10.71 \pm 0.54$ & $\mathrm{dH}_{2} \mathrm{O}$ & 0.0244 \\
& & $\mathrm{CoQ} 10$ & 0.1588 \\
\hline
\end{tabular}

Table S8 Effects of P3G on the egg laying of C. elegans under UV stress.

\begin{tabular}{|c|c|c|c|}
\hline Treatment & Mean \pm SD & Comparison & $p$-value \\
\hline $\mathrm{dH}_{2} \mathrm{O}$ & $31.79 \pm 0.860$ & & \\
\hline CoQ10 & $33.15 \pm 2.392$ & $\mathrm{dH}_{2} \mathrm{O}$ & 0.9978 \\
\hline \multirow[t]{2}{*}{$12.5 \mu \mathrm{g} / \mathrm{ml} \mathrm{P3G}$} & $31.35 \pm 0.813$ & $\mathrm{dH}_{2} \mathrm{O}$ & 0.9978 \\
\hline & & CoQ10 & $>0.9999$ \\
\hline \multirow[t]{2}{*}{$25 \mu \mathrm{g} / \mathrm{ml}$ P3G } & $33.32 \pm 0.789$ & $\mathrm{dH}_{2} \mathrm{O}$ & 0.8499 \\
\hline & & CoQ10 & 0.9995 \\
\hline \multirow[t]{2}{*}{$50 \mu \mathrm{g} / \mathrm{ml}$ P3G } & $34.32 \pm 3.757$ & $\mathrm{dH}_{2} \mathrm{O}$ & 0.7697 \\
\hline & & CoQ10 & 0.9978 \\
\hline
\end{tabular}


Table S9 Effects of P3G on the pharyngeal pumping of $C$. elegans under UV stress.

\begin{tabular}{|c|c|c|c|}
\hline Treatment & Mean \pm SD & Comparison & $p$-value \\
\hline $\mathrm{dH}_{2} \mathrm{O}$ & $165.60 \pm 2.941$ & & \\
\hline CoQ10 & $181.58 \pm 2.859$ & $\mathrm{dH}_{2} \mathrm{O}$ & $<0.0001$ \\
\hline \multirow[t]{2}{*}{$12.5 \mu \mathrm{g} / \mathrm{ml} \mathrm{P3G}$} & $171.20 \pm 4.486$ & $\mathrm{dH}_{2} \mathrm{O}$ & 0.0501 \\
\hline & & CoQ10 & $<0.0001$ \\
\hline \multirow[t]{2}{*}{$25 \mu \mathrm{g} / \mathrm{ml}$ P3G } & $176.80 \pm 2.037$ & $\mathrm{dH}_{2} \mathrm{O}$ & $<0.0001$ \\
\hline & & CoQ10 & 0.4372 \\
\hline \multirow[t]{2}{*}{$50 \mu \mathrm{g} / \mathrm{ml}$ P3G } & $175.80 \pm 2.445$ & $\mathrm{dH}_{2} \mathrm{O}$ & $<0.0001$ \\
\hline & & CoQ10 & 0.1832 \\
\hline
\end{tabular}

Table S10 Effects of P3G on the lifespan of C. elegans under oxidative stress.

\begin{tabular}{lccr}
\hline Treatment & Mean \pm SE & Comparison & $p$-value \\
\hline $\mathrm{dH}_{2} \mathrm{O}$ & $8.14 \pm 0.70$ & & \\
$\mathrm{CoQ} 10$ & $9.75 \pm 0.93$ & $\mathrm{dH}_{2} \mathrm{O}$ & 0.0491 \\
$12.5 \mu \mathrm{g} / \mathrm{ml} \mathrm{P3G}$ & $8.10 \pm 0.73$ & $\mathrm{dH}_{2} \mathrm{O}$ & 0.8461 \\
& & $\mathrm{CoQ} 10$ & 0.0762 \\
$25 \mu \mathrm{g} / \mathrm{ml} \mathrm{P3G}$ & $9.90 \pm 0.66$ & $\mathrm{dH}_{2} \mathrm{O}$ & 0.0480 \\
& & $\mathrm{CoQ}_{10}$ & 0.7170 \\
$50 \mu \mathrm{g} / \mathrm{ml} \mathrm{P3G}$ & $11.95 \pm 0.96$ & $\mathrm{dH}_{2} \mathrm{O}$ & 0.0004 \\
& & $\mathrm{CoQ} 10$ & 0.0326 \\
\hline
\end{tabular}

Table S11 Effects of P3G on the egg laying of C. elegans under oxidative stress.

\begin{tabular}{|c|c|c|c|}
\hline Treatment & Mean \pm SD & Comparison & $p$-value \\
\hline $\mathrm{dH}_{2} \mathrm{O}$ & $30.03 \pm 2.333$ & & \\
\hline CoQ10 & $31.90 \pm 0.447$ & $\mathrm{dH}_{2} \mathrm{O}$ & 0.99135 \\
\hline $12.5 \mu \mathrm{g} / \mathrm{ml} \mathrm{P3G}$ & $28.84 \pm 0.836$ & $\mathrm{dH}_{2}^{2} \mathrm{O}$ & $>0.9999$ \\
\hline $25 \mu \mathrm{g} / \mathrm{ml}$ P3G & $31.03 \pm 0.141$ & $\begin{array}{c}\mathrm{dH}_{2} \mathrm{O} \\
\mathrm{CoQ} 10\end{array}$ & $\begin{array}{r}>0.9999 \\
0.9135\end{array}$ \\
\hline $50 \mu \mathrm{g} / \mathrm{ml}$ P3G & $32.60 \pm 0.318$ & $\begin{array}{c}\mathrm{dH}_{2} \mathrm{O} \\
\mathrm{CoQ} 10\end{array}$ & $\begin{array}{r}0.9676 \\
>0.9999\end{array}$ \\
\hline
\end{tabular}

Table S12 Effects of P3G on the pharyngeal pumping of C. elegans under oxidative stress.

\begin{tabular}{|c|c|c|c|}
\hline Treatment & Mean \pm SD & Comparison & $p$-value \\
\hline $\mathrm{dH}_{2} \mathrm{O}$ & $150.80 \pm 2.941$ & & \\
\hline CoQ10 & $176.12 \pm 2.859$ & $\mathrm{dH}_{2} \mathrm{O}$ & $<0.0001$ \\
\hline $12.5 \mu \mathrm{g} / \mathrm{ml}$ P3G & $158.86 \pm 4.486$ & $\begin{array}{c}\mathrm{dH}_{2} \mathrm{O} \\
\mathrm{CoQ} 10\end{array}$ & $\begin{array}{r}0.2039 \\
<0.0001\end{array}$ \\
\hline $25 \mu \mathrm{g} / \mathrm{ml} \mathrm{P3G}$ & $167.27 \pm 2.037$ & $\begin{array}{c}\mathrm{dH}_{2} \mathrm{O} \\
\mathrm{CoQ} 10\end{array}$ & $\begin{array}{l}0.0006 \\
0.0129\end{array}$ \\
\hline $50 \mu \mathrm{g} / \mathrm{ml}$ P3G & $180.60 \pm 2.445$ & $\begin{array}{c}\mathrm{dH}_{2} \mathrm{O} \\
\mathrm{CoQ} 10\end{array}$ & $\begin{array}{r}<0.0001 \\
0.0832\end{array}$ \\
\hline
\end{tabular}

